\title{
A formação didática de professores da área de saúde
}

\author{
Narcisio Rios Oliveira' \\ Silvia Cristina de Oliveira Quadros²
}

Resumo: Este estudo consiste em uma pesquisa descritiva de base documental, com o objetivo de conhecer e avaliar a formação docente de professores da área de saúde de uma instituição de ensino superior da zona sul de São Paulo. Como resultado encontrou-se que a maioria dos profissionais é formada de mulheres (72\%); profissionais atuantes em apenas um curso de graduação (62\%), exercendo apenas a docência (62\%), com especialização em área de didática/ensino (17,2\%) e mestrado em educação (5,3\%). Com um corpo docente formado por profissionais de múltiplas áreas do conhecimento, a instituição, lócus desta pesquisa, incentiva e apoia a formação científica, didática e pedagógica desses profissionais, oportunizando capacitação por meio de ações e programas institucionais de formação continuada, como forma de aprimoramento profissional e científica de seus docentes, favorecendo, assim, o processo ensino-aprendizagem para os alunos dos cursos de enfermagem, fisioterapia e nutrição. Conclui-se que a formação docente na área de saúde requer do professor tanto o domínio do conhecimento técnico específico quanto o domínio didático-pedagógico, esse por sua vez, adquirido com o passar dos anos, através do processo de formação continuada e pós-graduação em nível lato sensu e stricto sensu.

Palavras-chave: formação didática; docente; educação superior.

\section{The didatics formation of teacher in the health area}

\footnotetext{
Abstract: This study consists of a descriptive documentary research, with the objective of knowing and evaluating the teacher training of college teachers in the health area of a higher education

1 Mestrado Profissional em Promoção da Saúde pelo Centro Universitário Adventista de São Paulo (Unasp). Professor do curso de Nutrição do Unasp e diretor do Comitê Técnico Científico da Associação Paulista de Nutrição (Apan) (gestão 2020-2022). E-mail: narcisiorios@gmail.com

2 Pós-doutorado em Educação pela Faculdade de Educação da Universidade de São Paulo (FEA-USP). Pró-reitora acadêmica associada do Centro Universitário Adventista de São Paulo, campus São Paulo (Unasp-SP). E-mail: silvia.oliveira@unasp.edu.br
} 
institution in the south zone of São Paulo. As a result, it was found that most of the professionals are women $(72 \%)$, professionals working in only one course $(62 \%)$, teaching only (62\%), with specialization in didactic/teaching area (17.2\%) and masters in education (5.3\%). With a faculty formed by professionals from multiple areas of knowledge, the institution studied encourages and supports the scientific, didactic and pedagogical training of these professionals through actions and programs of continuing education, as a way of professional and scientific improvement of their teachers, favoring thus teaching process for the students of nursing, physiotherapy and nutrition courses. It is concluded that teacher education in the area of health requires that teacher dominate specific technical knowledge and the pedagogical-didactic knowledge, and the professor acquired over the years, through the process of continuing education and graduate at the level lato sensu and strict sensu.

Keywords: college teacher; didactic formation; higher education.

A educação superior é um campo em frequente transformação e responsável pela formação de novos profissionais e pensadores, requerendo de seus mestres a constante atualização e familiarização com o desenvolvimento do saber técnico-científico.

Segundo Amarantes (2020), durante anos, o bom professor no ensino superior era visto apenas como aquele que conhecia o conteúdo disciplinar específico. Entretanto, atualmente, o professor deixou de efetuar o papel de mero reprodutor de conhecimento, passando a exercer uma educação crítica, capaz de influenciar o desenvolvimento de capacidades cognitivas e operacionais a partir da reflexão gerada pelas atividades dos conteúdos ministrados.

Diante das constantes transformações no exercício da profissão docente, Dallacosta (2020) destaca a responsabilidade quanto ao compromisso das instituições de ensino para com a formação e qualificação de seu corpo docente para um ensino de qualidade. Segundo ele, tais instituições devem "oportunizar acesso às diferentes técnicas de ensino, promover o debate e a visão crítica dos alunos, além de explorar a dimensão ética e política da formação em saúde", o que, para esse autor, são tidos como elementos capacitantes ao exercício da docência pelos profissionais de saúde.

Para Treviso e Costa (2017), muitos professores na área da saúde, embora especialistas em suas respectivas áreas, apresentam carência quanto à formação técnico-pedagógica. Segundo esses autores, ainda que a experiência e habilidade técnica possam contribuir na construção do conhecimento, essa contribuição não é o suficiente para o exercício da docência; em suas palavras, "o professor precisa ensinar o conteúdo, mas não somente isto", precisa de recursos, instrumentos e técnicas para mediar o ensino. 


\section{Importância da capacitação docente para o ensino superior ém saúde}

Segundo Paiva e Lopes (2017), os recursos e formação didática docente no exercício profissional dos professores do ensino superior são de fundamental importância, o que reforça a necessidade e atenção quanto à formação e qualificação acadêmico-profissional desses profissionais.

A formação continuada e o desenvolvimento profissional docente são vistos como condições essenciais, devido à complexidade do trabalho exercido pelo professor na educação superior, junto ao processo ensino-aprendizagem, exercendo papel fundamental na orientação e motivação dos alunos para a formação do conhecimento (TREVISO; COSTA, 2017). A formação continuada possibilita ao professor a reflexão e reelaboração dos conhecimentos adquiridos durante a formação inicial, capacitando-os a atender as complexidades da sua atuação profissional no âmbito do ensino-aprendizagem.

Nesse contexto, os cursos de pós-graduação apresentam-se como ferramenta à formação e capacitação didático-pedagógica para esses profissionais, haja vista a ausência de tal capacitação durante o período de formação inicial para os cursos de bacharelado na área da saúde (DALLACOSTA, 2020).

Ao professor demanda, além de características consolidadas, por meio de uma educação tecnicista e da transmissão de conhecimento, o processo constante da formação científica pedagógica, prática, técnica e política para o desenvolvimento de suas competências profissionais como educador, salientando a importância da competência didático-pedagógica, responsável por favorecer o processo de ensino-aprendizagem (DALLACOSTA, 2020; PIVETTA et al., 2019; TREVISO; COSTA, 2017).

O preparo docente, especialmente para a área da saúde, na educação superior, tem sido obtido pela realização de programas de pós-graduação, especialmente, em nível stricto sensu (mestrado e doutorado), onde, apesar da ausência da formação específica em educação, técnicas de ensino-aprendizagem e reflexões quanto ao mundo da docência, o aluno adquire domínio de conhecimento em área específica (RODRIGUES et al., 2020).

Cabe ressaltar que tais profissionais podem enfrentar ao longo do exercício docente uma série de problemas relacionados especialmente à ausência do preparo didático-pedagógico durante os anos de formação, o que reforça a necessidade da existência de tais conhecimentos a fim de proporcionar ao aluno o suporte necessário ao seu desenvolvimento acadêmico-científico, de maneira que ele absorva de forma mais eficaz o que lhe é transmitido (TREVISO; COSTA, 2017).

Ao tratarmos sobre a docência universitária, não devemos considerar tal processo levando em consideração apenas a presença e/ou desenvolvimento de habilidades técnico-científicas, mas também considerar as habilidades interativas e integrativas, que propiciarão ao professor a compreensão da singularidade de seus alunos através da capacidade didático-pedagógica em que esses mestres terão de "ligar e religar os saberes teórico-práticos" (LIMA; PALVA; COSTA, 2017). Essas realidades refor- 
çam, portanto, a ideia de Treviso e Costa (2017), ao afirmar que "somente saber a técnica ou o conteúdo não é suficiente para poder ensinar, é necessário também domínio na área pedagógica".

Levando em consideração a importância da formação didático-pedagógica para a qualificação de professores para o ensino superior, este estudo busca proporcionar uma reflexão quanto à formação acadêmico-profissional de professores dos cursos de saúde. Para tanto, elegeu-se uma instituição de ensino, um centro universitário confessional, localizado na Zona Sul da cidade de São Paulo, no que tange à formação didático-pedagógica desses profissionais. A escolha dessa instituição foi realizada por localizar-se em uma região populosa e por ter ela um papel importante na região ao ofertar cursos de saúde.

\section{Caracterizacão da instituicão lócus do estudo e peŕcurso metodólógico}

A Zona Sul é considerada a região mais populosa da cidade de São Paulo, apresentando grandes contrastes em nível social e econômico. Dentro desse quadro de diferentes realidades socioeconômicas e culturais, já que a região é limítrofe a outros três grandes municípios da Região Metropolitana de São Paulo, encontra-se a instituição escolhida para o desenvolvimento dessa pesquisa. Segundo Tavares (2008), sua presença "nessa região tem ampliado oportunidades educacionais, em saúde, cidadania e qualidade de vida de comunidades adjacentes", sendo oferecidos à comunidade cursos desde a educação infantil até a pós-graduação.

A instituição escolhida é formada por três campi, estando dois no interior de São Paulo e um na capital (Zona Sul de São Paulo). É uma instituição centenária, fundada em 1915 por missionários alemães, e atualmente conta com cerca de 5.400 alunos, apenas no campus da Zona Sul de São Paulo (onde se encontram os cursos de Enfermagem, Fisioterapia e Nutrição). Ela é formada por alunos das mais variadas regiões do Brasil e do mundo, distribuídos nos mais diversos cursos desde a educação infantil até a pós-graduação stricto sensu.

A instituição tem como visão: "Ser uma instituição educacional reconhecida pela excelência nos serviços prestados, pelos seus elevados padrões éticos e pela qualidade pessoal e profissional de seus egressos" (Documento Institucional, 2018). Para a obtenção de tais padrões de qualidade profissional a seus egressos é necessário, portanto, um corpo docente composto por professores devidamente qualificados e capacitados ao ensino e formação profissional de seus discentes.

Assim, após escolhida a instituição, objeto deste estudo, optou-se pela realização de um estudo descritivo de base documental, que permite realizar a "descrição das características de determinada população ou fenômeno". A base de dados documental é definida como aquela que "vale-se de materiais que não receberam ainda um tratamento analítico, ou que ainda podem ser reelaborados de acordo com os objetivos da pesquisa" (GIL, 2008). 
Para a produção desta pesquisa, realizou-se, inicialmente, uma busca no portal da instituição pela internet, a fim de identificar o corpo docente dos cursos de enfermagem, fisioterapia e nutrição da instituição, sendo encontrado um número de 50 profissionais. Durante a identificação, realizou-se o levantamento dos nomes completos disponíveis no sítio virtual e cursos aos quais o docente encontrava-se vinculado, a fim de listá-los e realizar o processo de busca das informações junto a base de dados da Plataforma Lattes, que serviu como instrumento fonte de dados para a realização deste trabalho.

Com base nas informações coletadas no Currículo Lattes dos docentes, foi possível estruturar a análise do corpo docente dos cursos da área de saúde da instituição eleita para a realização deste estudo.

De acordo com a visão institucional, a Instituição de Ensino Superior (IES) estudada tem procurado desenvolver uma política de formação continuada, a fim de possibilitar ao seu quadro docente uma maior aproximação e aprofundamento dos conhecimentos didático-pedagógicos, por meio do seu Plano de Qualificação Docente. Através dele são desenvolvidos programas de valorização da docência como o Programa de Aperfeiçoamento Docente (PAD), que visa auxiliar esse profissional na obtenção de titulação, e o Programa de Apoio Pedagógico (Proap), no qual, por meio do contato profissional com novas teorias didático-pedagógicas, metodologias, estratégias e tecnologias de ensino, o profissional adquire conhecimentos teóricos e práticos no campo do ensino superior, tornando-o um profissional capacitado a desenvolver ações criativas e inovadoras (Documento Institucional, 2017).

Para Ogawa e Vosgerau (2017), a formação continuada é encarada como um aspecto fundamental no processo de formação e desenvolvimento docente. Nesse contexto, a IES estudada apresenta uma série de programas e projetos a fim de promover o desenvolvimento técnico, didático-científico e educacional no intuito de promover as atribuições profissionais de seu corpo docente. Tais ações vão desde o suporte e apoio pedagógico, por meio do Programa de Apoio Pedagógico ao Docente (Proap), até o incentivo financeiro por meio de auxílios institucionais à qualificação docente, necessários ao constante aperfeiçoamento profissional e do conhecimento técnico-científico que requer o ensino superior na área da saúde (Documento Institucional, 2017). Esses programas e projetos demonstram, assim, o compromisso para com a qualificação profissional e formação daqueles que estão em contato constante e direto com seus educandos.

\section{Processo de coleta de dados}

O Currículo Lattes, disponibilizado através da Plataforma Lattes (BRASIL, 2018a), é uma ferramenta padronizada, on-line e gratuita, que possibilita aos usuários interessados o cadastramento de informações pessoais, profissionais, de produções bibliográficas, técnicas e artísticas, as quais serão disponibilizadas na rede mundial de computadores, possibilitando o acesso a essas informações por qualquer indivíduo e instituição, a fim de conhecer e avaliar informações profissionais e acadêmicas de forma acessível, padronizada e confiável (SILVA; SANTOS, 2010). 
Para Souza (2010), o currículo Lattes é apontado como uma "máquina de controle microscópio do comportamento das produções acadêmicas", sendo responsável pelo registro, classificação, divisão, qualificação, disciplina e avaliação de todos os registros contidos em seu banco de dados, cujas informações são fornecidas por seus usuários, especialmente pesquisadores, estudantes e membros da comunidade acadêmica de maneira livre e voluntaria.

A coleta de dados na Plataforma Lattes (BRASIL, 2018b) ocorreu entre os meses de maio e junho de 2018, com a realização de buscas individuais das informações docentes por meio da ferramenta "Busca Currículo Lattes (Busca Simples)", utilizando, para tal, o nome completo do docente, com busca nas bases "Doutores" e "Demais pesquisadores (Mestres, Graduados, Estudantes, Técnicos etc.)", de nacionalidade "Brasileira" e "Estrangeira". Após a realização da busca simples e identificação do profissional, realizou-se a verificação do Currículo Lattes disponibilizado na plataforma, os quais foram arquivados em pasta específica, para posterior tabulação das seguintes variáveis: sexo; data de atualização do currículo; curso em que leciona; área em que atua; anos de atuação em docência; tipo de instituição da formação inicial; ano, grau e área de formação.

Com base nesses dados, configurou-se uma planilha em Excel ${ }^{\circledR}$. Os critérios de exclusão utilizados foram: inexistência do currículo disponível na Plataforma Lattes e cuja atualização tenha ocorrido antes dos últimos seis meses (anterior a janeiro de 2018).

\section{Caracterização da formação dos docentes da' instituição}

O número de professores dos cursos de enfermagem, fisioterapia e nutrição da instituição em evidência foi de 50 indivíduos, todos com currículo disponível na Plataforma Lattes, sendo a última atualização mais antiga do currículo do mês de janeiro de 2018 e a mais nova do mês de junho de 2018.

Conforme tabela 1, constatamos que a maioria dos professores dos cursos de saúde da instituição estudada era formada por profissionais do sexo feminino (72\%, totalizando 36 professores), atuantes em um curso (62\%, totalizando 31$)$, sendo a maioria do curso de enfermagem ( $26 \%$, totalizando 13), seguido por professores atuantes nos três cursos (Enfermagem, Fisioterapia e Nutrição) (24\%, totalizando 12$)$, exercendo apenas a docência (62\%, totalizando 31$)$, sendo que $18 \%$ (9 professores) atuam na área da docência em conjunto com o exercício profissional da sua área específica de formação. Quanto aos anos de atuação em docência, a maioria dos professores possui entre 0 e 5 anos, seguidos por profissionais entre 6 e 10 anos, correspondendo respectivamente a 24\% (12 professores) e $22 \%$ ( 11 professores). 
Tabela 1 - Caracterização de professores dos cursos de saúde de um centro universitário privado da Zona Sul de São Paulo, capital, 2018.

\begin{tabular}{|c|c|c|c|c|c|}
\hline VARIÁVEL & NÚMERO & $\%$ & VARIÁVEL & NÚMERO & $\%$ \\
\hline \multicolumn{3}{|l|}{ SEXO } & \multicolumn{3}{|l|}{ ÁREA DE ATUAÇÃO } \\
\hline Masculino & 14 & $28 \%$ & Docência & 31 & $62 \%$ \\
\hline Feminino & 36 & $72 \%$ & Docência e gestão & 05 & $10 \%$ \\
\hline Total & 50 & $100 \%$ & Docência e específica & 09 & $18 \%$ \\
\hline \multicolumn{3}{|c|}{ QUANTIDADE DE CURSOS EM QUE ATUA } & $\begin{array}{l}\text { Docência, gestão e } \\
\text { específica }\end{array}$ & 05 & $10 \%$ \\
\hline 1 curso & 31 & $62 \%$ & Total & 50 & $100 \%$ \\
\hline 2 cursos & 07 & $14 \%$ & \multicolumn{3}{|c|}{ ANOS DE FORMAC̣ÃO } \\
\hline 3 cursos & 12 & $24 \%$ & 0 a 5 anos & 00 & $0 \%$ \\
\hline Total & 50 & $100 \%$ & $>6$ e $<10$ anos & 04 & $8 \%$ \\
\hline \multicolumn{3}{|c|}{ DOCENTE POR CURSO } & $>11$ e $<15$ anos & 08 & $16 \%$ \\
\hline Enfermagem & 13 & $26 \%$ & $>16$ e $<20$ anos & 14 & $28 \%$ \\
\hline Fisioterapia & 09 & $18 \%$ & $>21$ anos & 24 & $48 \%$ \\
\hline Nutrição & 09 & $18 \%$ & Total & 50 & $100 \%$ \\
\hline $\begin{array}{l}\text { Enfermagem e } \\
\text { fisioterapia }\end{array}$ & 01 & $2 \%$ & \multicolumn{3}{|c|}{ ANOS DE ATUAÇÃO EM DOCÊNCIA } \\
\hline $\begin{array}{l}\text { Enfermagem e } \\
\text { nutrição }\end{array}$ & 02 & $4 \%$ & 0 a 5 anos & 12 & $24 \%$ \\
\hline $\begin{array}{l}\text { Fisioterapia e } \\
\text { nutrição }\end{array}$ & 04 & $8 \%$ & $>6$ e $<10$ anos & 11 & $22 \%$ \\
\hline \multirow{2}{*}{$\begin{array}{l}\text { Enfermagem, } \\
\text { nutrição e fisio- } \\
\text { terapia }\end{array}$} & \multirow{2}{*}{12} & \multirow{2}{*}{$24 \%$} & $>11$ e $<15$ anos & 10 & $20 \%$ \\
\hline & & & $>16$ e $<20$ anos & 10 & $20 \%$ \\
\hline \multirow[t]{2}{*}{ Total } & 50 & $100 \%$ & $>21$ anos & 7 & $14 \%$ \\
\hline & & & Total & 50 & $100 \%$ \\
\hline
\end{tabular}

Fonte: elaborado pelos autores

No que se refere à formação desses profissionais (Tabela 2), a maioria (48\%) deles tinha mais de 21 anos de formados na graduação inicial, sendo que $90 \%$ possuíam apenas um curso de graduação, $8 \%$ dois cursos e $2 \%$ quatro cursos. O principal curso de graduação desses profissionais foi o de enfermagem (31,6\%), seguido pelos cursos de fisioterapia (19,3\%), nutrição (14\%) e ciências biológicas $(8,8 \%)$. Havia também profissionais formados em outros cursos, que, agrupados, correspondiam a 26,3\%, sendo eles: biomedicina, biblioteconomia, educação física, farmácia, filosofia, história, letras, pedagogia, psicologia e teologia.

Essa diversidade da formação docente, conforme encontrada, pode proporcionar aos cursos uma visão multiprofissional, uma vez que a instituição tem para esses cursos um currículo integrado, 
em que o docente pode ministrar aulas em uma sala contendo alunos dos três cursos (enfermagem, fisioterapia e nutrição) indistintamente.

Tabela 2 - Formação dos professores dos cursos de saúde de um centro universitário privado da Zona Sul de São Paulo, capital, 2018.

\begin{tabular}{|c|c|c|c|c|c|}
\hline VARIÁVEL & NÚMERO & $\%$ & VARIÁVEL & NÚMERO & $\%$ \\
\hline \multicolumn{3}{|c|}{ ANOS DE FORMAC̣ÃO } & \multicolumn{3}{|c|}{ QUANTIDADE DE MESTRADOS } \\
\hline 0 a 5 anos & 00 & $0 \%$ & Nenhum & 12 & $24 \%$ \\
\hline$>6$ e $<10$ anos & 04 & $8 \%$ & Um & 38 & $76 \%$ \\
\hline$>11$ e $<15$ anos & 08 & $16 \%$ & Dois ou mais & 0 & $0 \%$ \\
\hline$>16$ e $<20$ anos & 14 & $28 \%$ & Total & 50 & $100 \%$ \\
\hline$>21$ anos & 24 & $48 \%$ & \multicolumn{3}{|c|}{ ÁREAS DE MESTRADO } \\
\hline Total & 50 & $100 \%$ & Saúde Pública/Coletiva & 06 & $15,8 \%$ \\
\hline \multicolumn{3}{|c|}{ QUANTIDADE DE GRADUAC̣ÕES } & Ciências & 04 & $10,5 \%$ \\
\hline Nenhum & 00 & $0 \%$ & Enfermagem & 04 & $10,5 \%$ \\
\hline Uma & 45 & $90 \%$ & Medicina & 04 & $10,5 \%$ \\
\hline Duas & 04 & $8 \%$ & Educação & 02 & $5,3 \%$ \\
\hline Três & 00 & $0 \%$ & Outras áreas da Saúde & 09 & $23,7 \%$ \\
\hline Quatro & 01 & $2 \%$ & Outras áreas diversas & 09 & $23,7 \%$ \\
\hline Total & 50 & $100 \%$ & Total & 38 & $100 \%$ \\
\hline \multicolumn{3}{|c|}{ CURSO DE GRADUAC̣ÃO } & \multicolumn{3}{|c|}{ QUANTIDADE DE DOUTORADOS } \\
\hline Ciências Biológicas & 05 & $8,8 \%$ & Nenhum & 32 & $64 \%$ \\
\hline Enfermagem & 18 & $31,6 \%$ & Um & 18 & $36 \%$ \\
\hline Fisioterapia & 11 & $19,3 \%$ & Dois ou mais & 00 & $0 \%$ \\
\hline Nutrição & 08 & $14 \%$ & Total & 50 & $100 \%$ \\
\hline Outros & 15 & $26,3 \%$ & \multicolumn{3}{|c|}{ ÁREAS DE DOUTORADO } \\
\hline Total & 57 & $100 \%$ & Ciências Biológicas & 2 & $11,1 \%$ \\
\hline \multicolumn{3}{|c|}{ QUANTIDADE DE ESPECIALIZAC̣ÕES } & Ciências & 3 & $16,7 \%$ \\
\hline Nenhuma & 08 & $16 \%$ & Saúde Pública/Coletiva & 2 & $11,1 \%$ \\
\hline Uma & 30 & $60 \%$ & Medicina & 5 & $27,8 \%$ \\
\hline Duas & 09 & $18 \%$ & Outros & 6 & $33,3 \%$ \\
\hline Três & 02 & $4 \%$ & Total & 18 & $100 \%$ \\
\hline Quatro & 01 & $2 \%$ & \multicolumn{3}{|c|}{ QUANTIDADE DE PÓS-DOUTORADOS } \\
\hline Total & 50 & $100 \%$ & Nenhum & 47 & $94 \%$ \\
\hline \multicolumn{3}{|c|}{ AREAS DE ESPECIALIZAÇÃO } & Um & 3 & $6 \%$ \\
\hline $\begin{array}{l}\text { Administração/ } \\
\text { Gestão }\end{array}$ & 6 & $10,3 \%$ & Total & 50 & $100 \%$ \\
\hline Didática/Ensino & 10 & $17,2 \%$ & \multicolumn{3}{|c|}{ ONDE REALIZOU O PÓS-DOUTORADO } \\
\hline Enfermagem/Saúde & 13 & $22,4 \%$ & Brasil & 2 & $67,7 \%$ \\
\hline
\end{tabular}




\begin{tabular}{|l|c|c|l|l|c|}
\hline Fisiologia & 4 & $6,9 \%$ & Estados Unidos & 1 & $33,3 \%$ \\
\hline Fisioterapia/Saúde & 9 & $15,5 \%$ & Outros & 0 & $0 \%$ \\
\hline Nutrição/Saúde & 4 & $6,9 \%$ & Total & 3 & $100 \%$ \\
\hline Psicopedagogia & 4 & $6,9 \%$ & & & \\
\hline Outros & 8 & $13,8 \%$ & & & \\
\hline Total & 58 & $100 \%$ & & & \\
\hline
\end{tabular}

Fonte: Elaborado pelos autores

A Lei de Diretrizes Básicas da Educação (LDB) (BRASIL, 2017a), em seu artigo 66, afirma que "a preparação para o exercício do magistério superior far-se-á em nível de pós-graduação, prioritariamente em programas de mestrado e doutorado". E ao analisarmos a formação dos professores estudados, verificou-se que a maioria dos profissionais possuía uma especialização (60\%), sendo a principal na área enfermagem/saúde, seguido pelas áreas da didática/ensino e fisioterapia/saúde, o que corresponde a $22,4 \%, 17,2 \%$ e $15,5 \%$, respectivamente.

Dos professores analisados, 76\% possuíam mestrado, cuja principal área de concentração é a saúde pública/coletiva (15,8\%), seguido por ciências, enfermagem e medicina (10,5\%), enquanto a área de educação corresponde a 5,3\%. Quanto ao doutorado, 36\% dos profissionais estudados possuíam essa titulação, sendo a maioria na área de medicina $(27,8 \%)$ e $6 \%$ de todos os profissionais estudados eram possuidores de pós-doutorado.

Rodrigues e colaboradores (2020) destacam o papel e responsabilidade da pós-graduação diante do potencial nela existente para a formação de docentes para o ensino superior, instrumentalizando-os na adoção de amplas estratégias e problematizações. Elas proporcionam aos alunos um ambiente de reflexão, a partir do processo ensino-aprendizagem com embasamento teórico e atendendo os objetivos da formação a qual se propõe lecionar, mediante a reflexão prévia de seu papel e função enquanto ser político e social, transformador da realidade.

Ao identificar a percepção de profissionais da área da saúde quanto à formação para o exercício da atividade docente, por meio de um estudo exploratório com uma amostra de 85 professores de dez cursos de graduação na área da saúde de uma IES privada do estado do Rio Grande do Sul, Treviso e Costa (2017) destacaram a fala de um profissional ao afirmar que "mesmo que houvesse significativa carga horária para formação inicial nos cursos da área da saúde, ainda seria necessária uma formação pedagógica continuada".

Deve-se, portanto, destacar aqui que tal formação é incentivada e disponibilizada aos profissionais aqui estudados, por meio de ações e instrumentos institucionais de promoção e apoio técnico, pedagógico e científico ao docente pelas mais variadas abordagens existentes. Visto que, embora a especialização seja uma das formas para capacitação acadêmico-profissional do docente na área da saúde, destacam-se também outras ferramentas como leituras, oficinas, participação em 
cursos e eventos, pesquisa e produção científica, participação em bancas de trabalho de conclusão de curso, participação em grupos de pesquisa e eventos científicos, troca entre pares e alunos, feedback em avaliação discente e em autoavaliação, entre outras ações de formação formais e/ou informais (TREVISO; COSTA, 2017).

Para Keller-Franco, Kuntze e Costa (2012), a prática de um Currículo Integrado Multiprofissional entre os cursos de enfermagem, fisioterapia e nutrição existente na instituição estudada procura despertar no aluno uma abordagem mais ampla, complexa e integrativa do conhecimento, por meio da ênfase na integralidade do cuidado e no desenvolvimento das competências necessárias ao trabalho em equipes multiprofissionais.

Dessa forma, acredita-se que, essa integração curricular seja o motivo pelo qual exista essa composição multidisciplinar na formação dos professores da IES, lócus da pesquisa, que torna o processo de transmissão de conhecimento integrado e contextualizado. Os alunos, a partir do contato com seus professores de diferentes formações, poderão absorver deles o conhecimento partilhado por meio de diferentes perspectivas, favorecendo, assim, a prática profissional multidisciplinar de seus alunos e futuros profissionais.

O Marco Regulatório do Ensino Superior, instituído pelo Decreto de n 9.235, de 15 de dezembro de 2017 (BRASIL, 2017b), institui que um dos critérios para que instituições de ensino superior privadas possam solicitar o recredenciamento como centro universitário é "um terço do corpo docente possuir titulação acadêmica de mestrado ou doutorado". No presente estudo, pudemos constatar que dentre os profissionais estudados, esse número foi facilmente superado. Porém, destaca-se que a análise aqui realizada inclui apenas os cursos da área da saúde, não sendo avaliados os demais cursos da instituição, estendendo-se, portanto, a possibilidade de novos estudos a fim de avaliar e analisar a formação docente dos demais professores da IES estudada.

\section{Considerações finais}

Diante do exposto, concluímos que o corpo docente dos cursos da IES apresenta formação inicial alinhada às respectivas áreas do conhecimento, no qual destacam-se as formações na área da saúde, em especial a área da enfermagem, cabendo salientar que o grau de titulação é superior ao número mínimo exigido pela legislação vigente aos professores dos cursos de área da saúde da IES estudada.

O aprimoramento da formação dos docentes, além do mestrado e doutorado, é garantido para além do saber da experiência, uma vez que a instituição desenvolve programas de apoio pedagógico para a promoção da educação continuada, especialmente voltada a uma formação integral e multidisciplinar do conhecimento, além do aprimoramento didático-pedagógico. Tais fatos reforçam, ainda, a importância e o interesse institucional na formação em nível de pós-graduação de seus profissionais 
na área da docência universitária, sendo inclusive esse um curso oferecido pela instituição estudada e ofertada aos seus servidores.

\section{Referências}

AMARANTES, L. H. Considerações sobre a formação e a atuação do profissional docente do ensino superior nos cursos de ciências da saúde. Revista renovare de saúde e meio ambiente, v. 7, n. 2, 2020.

BRASIL - Conselho Nacional de Desenvolvimento Científico e Tecnológico. Sobre a plataforma Lattes. 2018a. Disponível em: https://bit.ly/3wKnuOr. Acesso em: 01 out. 2018.

BRASIL - Conselho Nacional de Desenvolvimento Científico e Tecnológico. Buscar Currículo Lattes. 2018b. Disponível em: https://bit.ly/3qckB62. Acesso em: 19 abr. 2018.

BRASIL - Senado Federal. LDB: Lei de diretrizes e bases da educação nacional. Brasília: Senado Federal, 2017a. 58p. Disponível em: https://bit.ly/3wMnAVg. Acesso em: 19 abr. 2021.

BRASIL. Decreto n. 9.235, de 15 de dezembro de 2017. Dispõe sobre o exercício das funções de regulação, supervisão e avaliação das instituições de educação superior e dos cursos superiores de graduação e de pós-graduação no sistema federal de ensino. Brasília, 2017b. Disponível em: <https://bit. ly/3cTq8ZN>. Acesso em: 19 abr. 2021.

DALLACOSTA, F. M. Docência em saúde: breve reflexão sobre esta prática profissional. Revista eletrônica pesquiseduca, v. 12, n. 26, p. 8-17, 2020.

GIL, A. C. Métodos e técnicas de pesquisa social. 6 ed. São Paulo: Atlas, 2008.

KELLER-FRANCO, E.; KUNTZE, T. D.; COSTA, L. S. Inovação Curricular na Formação dos Profissionais da Saúde. Revista e-Curriculum, São Paulo, v. 8, n. 2, p. 1-14, 2012.

LIMA, R. B.; PALVA, A. J. O. M.; COSTA, F. P. S. A importância da formação do professor enfermeiro no ensino superior. In: PAROSCHI, E.; COSTA, F.; KUNZ, V. (Orgs.). Docência universitária em foco: à docência universitária nas multiáreas. Engenheiro Coelho: Unaspress, 2017

OGAWA, M. N.; VOSGERAU, D. A. R. Docência no Ensino Superior: características de uma formação. In: Congresso Nacional de Educação - Educere, 2017, Curitiba. Anais do XIII Educere. Curitiba: PUCPRess, 2017. p. 6.443-6.458. Disponível em: https://bit.ly/3wKhbcZ. Acesso em: 19 abr. 2021.

PAIVA, Y, U. V.; LOPES, J. F. A necessidade de um conhecimento didático na docência universitária. In: VASQUES, A. R.; MUCKENBERGER, E. (Orgs.). Docência universitária: desafios e tendências na educação a distância. Engenheiro Coelho: Unaspress, 2017.

PIVETTA, H. M. F. et al. Percalços da Docência Universitária nas Ciências da Saúde. Educação \& realidade, v. 44, n. 1, e75639, 2019.

RODRIGUES, M. E. C. A pós-graduação com lócus de formação para a docência: uma experiência com metodologias ativas de ensino-aprendizagem na área da saúde. Barbarói, n. 56, p. 104-126, 2020.

SILVA, C. E. E.; SANTOS, C. D. S. A plataforma Lattes como modelo de padronização de currículo em processo de recrutamento e seleção. Revista administração em diálogo, v. 12, n. 3, p. 34-59, 2010. 
SOUZA, A. L. Panopticon virtual da contemporaneidade: o Currículo Lattes como possibilidade de controle e vigilância na área de Arte. Dissertação (Mestrado em Educação) - Universidade Presbiteriana Mackenzie, São Paulo, 2010.

TAVARES, C. Z. Formação em avaliação: a formação de docentes no enfrentamento de um processo de avaliação a serviço da aprendizagem. 2008. 246 f. Tese (Doutorado em Educação) - Pontifícia Universidade Católica de São Paulo, São Paulo, 2008.

TREVISO, P.; COSTA, B. E. P. Percepção de profissionais da área da saúde sobre a formação em sua atividade docente. Texto \& contexto enfermagem, v. 26, n. 1, p. 1-9, 2017.

UNASP-CENTRO UNIVERSITÁRIO ADVENTISTA DE SÃO PAULO. Manual do professor. Engenheiro Coelho: UNASP, 2017. Disponível em: https://bit.ly/3gFHqvl. Acesso em: 19 abr. 2021.

UNASP-CENTRO UNIVERSITÁRIO ADVENTISTA DE SÃO PAULO. Relatório de autoavaliação institucional 2017. São Paulo: UNASP, 2018. Disponível em: https://bit.ly/3vllYdS. Acesso em: 19 abr. 2021. 